\title{
Intrauterine Growth Restriction Is Associated with Changes in Polyunsaturated Fatty Acid Fetal-Maternal Relationships
}

\author{
IRENE CETIN, NICCOLÒ GIOVANNINI, GIOIA ALVINO, CARLO AGOSTONI, ENRICA RIVA, \\ MARCELLO GIOVANNINI, AND GIORGIO PARDI \\ Departments of Obstetrics and Gynecology [I.C., N.G., G.A., G.P.] and Pediatrics [C.A., E.R., M.G.], \\ DMCO Ospedale San Paolo, University of Milano, 20142 Milano, Italy
}

\begin{abstract}
Fetuses with intrauterine growth restriction (IUGR) are at increased risk of death and disease during neonatal, pediatric, and adult life. Postnatal deficits in essential fatty acids have been associated with the neural and vascular complications of premature neonates. We studied whether fetal-maternal fatty acid relationships are already impaired in utero in IUGR fetuses. Fetal (F) and maternal (M) fatty acid profiles were determined in utero in 11 normal [appropriate for gestational age (AGA)] and in 10 IUGR fetuses by fetal blood sampling (FBS) between 19 and 39 wk. Total plasma fatty acid concentrations were significantly higher in $\mathrm{M}$ than in F of both AGA (M: $2.03 \pm 0.53 \mathrm{mg} / \mathrm{mL}$; F: $0.64 \pm 0.29 \mathrm{mg} / \mathrm{mL} ; p<0.001)$ and IUGR (M: $2.16 \pm 0.59$ $\mathrm{mg} / \mathrm{mL} ; \mathrm{F}: 0.73 \pm 0.17 \mathrm{mg} / \mathrm{mL} ; p<0.001)$. The $\mathrm{F} / \mathrm{M}$ ratio was significantly higher for linoleic acid (AGA: $0.36 \pm 0.09$; IUGR: $0.52 \pm 0.12 ; p<0.01)$ and significantly lower for the long-chain polyunsaturated fatty acid docosahexaenoic acid (AGA: $1.94 \pm$ 0.32; IUGR: $1.25 \pm 0.19 ; p<0.05$ ) and arachidonic acid (AGA: $2.35 \pm 0.35 \%$; IUGR: $2.04 \pm 0.3 \% ; p<0.05)$ in IUGR compared with AGA pregnancies. The differences observed in the relative amounts but not in total plasma concentrations of fatty acid fetal-maternal relationships in pregnancies associated
\end{abstract}

\section{ABSTRACT}

with IUGR could be related to inadequate transplacental supply as well as to a fetal lack of the enzymes necessary for elaboration of these metabolically relevant conditionally essential fatty acids. These differences might have a role in determining the biochemical environment leading to the neural and vascular complications associated with IUGR. (Pediatr Res 52: 750-755, 2002)

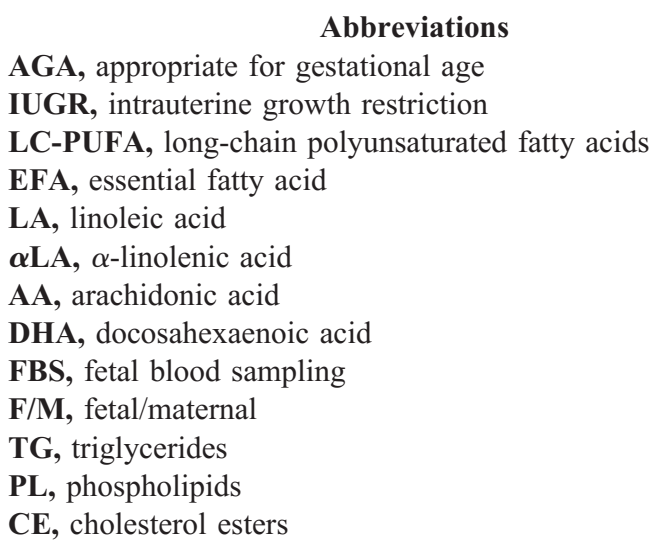

IUGR is a condition associated with placental insufficiency as a result of shallow trophoblast invasion during the early stages of gestation (1). Besides its relevance as an important cause of perinatal mortality and morbidity, a great number of studies have reported that low birth weight is a major determinant of cardiovascular disease and glucose intolerance in adult life (2-4). Knowledge about this condition has been expanded in the last decade by exploiting the possibility of

Received October 17, 2001; accepted April 22, 2002

Correspondence: Irene Cetin, M.D., Obstetrics and Gynecology, San Paolo Department of Medicine, Surgery and Dentistry, University of Milano School of Medicine, via A. di Rudini', 8, 20142 Milano, Italy; e-mail: irene.cetin@unimi.it

Supported by an European Economic Community (EEC) grant BMH4-98-3621 and a grant from the Italian Ministry of University and Scientific and Technologic Research (Ministero Università e Ricerca Scientifica e Tecnologica: MURST) and CNR (Consiglio Nazionale delle Ricerche).

DOI: 10.1203/01.PDR.0000031923.07968.D5 obtaining fetal blood in utero by FBS. By this means, placental supply of amino acids has been shown to be significantly altered in pregnancies associated with $\operatorname{IUGR}(5,6)$, even when oxygenation and acid-base balance are not impaired (7).

During the third trimester intrauterine growth of the fetus is accompanied by a large deposition of fat tissue (8). Fetal fat content increases from 0.7 to $3.1 \mathrm{~g} / 100 \mathrm{~g}$ weight at $25 \mathrm{wk}$ to 10.2 to $16.1 \mathrm{~g} / 100 \mathrm{~g}$ weight at term (9). LC-PUFA are deposited in large amounts in the fetal brain during the period of maximum brain growth in the last trimester of pregnancy and first months of postnatal life (10-12). The incorporation of preformed AA and DHA into the developing brain is selective and more than 10 times faster than incorporation via the biosynthetic routes from LA and $\alpha \mathrm{LA}(13,14)$. Because the placenta does not seem to desaturate LA and $\alpha \mathrm{LA}$, most of the $\omega-3$ and $\omega-6$ fatty acid structure acquired by the fetus in 
utero has to cross the placenta, and in normal pregnancies the biggest determinant of fatty acid delivery to the fetus is the concentration in the maternal circulation (15), which is strongly related to maternal fatty acid intake.

EFAs of the $\omega-3$ and $\omega-6$ series are mainly provided to the placenta by nonesterified fatty acids derived from TGs by lipoproteins of maternal adipose tissue and liver (16). The percent composition of EFAs and LC-PUFA has been reported as significantly different in fetal than in maternal blood, indicating an important role of the placenta in handling the fatty acid supply to the fetus $(17,18)$.

The aim of the present study is 1) to investigate fatty acid composition of maternal and fetal blood in the second half of gestation, and 2) to evaluate fetal-maternal fatty acid relationships in normal and IUGR pregnancies.

\section{METHODS}

The studies were performed in the Departments of Obstetrics and Gynecology and of Pediatrics of the San Paolo Hospital. The protocol was approved by the San Paolo Institute Board. Informed consent was obtained from all pregnant women.

Subjects. Twenty-one pregnancies were studied at the time of FBS performed between 19 and 39 wk of gestation. Gestational age was determined according to the onset of the last menstrual period and by an ultrasonographic examination performed before $20 \mathrm{wk}$ of gestation.

Patterns of intrauterine fetal growth were defined by ultrasound performed during pregnancy and confirmed at birth. Two groups of pregnancies were studied: 1) 11 pregnancies carried normally grown fetuses that were AGA at birth according to Italian standards for birth weight and gestational age (19). These pregnant women underwent FBS for prenatal diagnosis (rapid karyotyping, maternal infections, maternal thrombocytopenia) and demonstrated absence of the pathology (normal group); and 2) 10 pregnancies carried IUGR fetuses identified by serial ultrasound examinations. In utero measurements of abdominal circumferences of IUGR fetuses were below the 10th percentile of reference values for fetuses of similar ages, and they showed a decrease of more than 40 percentiles from their growth curve. In these cases FBS was performed for rapid karyotyping and biochemical assessment of oxygenation and acid-base values as part of our routine clinical protocol (6). Growth restriction was confirmed at birth if the neonatal weight was below the 10th percentile according to Italian standards for birth weight and gestational age (19).

All fetuses had normal karyotypes and no malformations at birth. Exclusion criteria for both normal and IUGR pregnancies were subsequent development of gestational diabetes or pregnancy-induced hypertension.

The maternal characteristics, gestational age, and fetal weights of the AGA and IUGR population are presented in Table 1.

Fetal blood sampling. The procedure was performed after an overnight fast, without maternal anesthesia. Fetal blood was obtained from the umbilical vein. The site of sampling was assessed by ultrasonographic imaging with a $5-\mathrm{MHz}$ sector transducer, by determination of nonpulsatile flow in the vessel,
Table 1. Characteristics of the study population

\begin{tabular}{ccc}
\hline & AGA & IUGR \\
\hline Maternal age & 28.2 & 29.6 \\
$(\mathrm{y})$ & $(4.5)$ & $(4.4)$ \\
Maternal BMI & 24.1 & 25.4 \\
$\left(\mathrm{~kg} / \mathrm{m}^{2}\right)$ & $(4.5)$ & $(4.3)$ \\
FBS & 28.2 & 28.6 \\
$(\mathrm{wk})$ & $(8.0)$ & $(4.3)$ \\
Delivery & 39.5 & $34.1^{*}$ \\
(wk) & $(1.0)$ & $(4.6)$ \\
Fetal weight & 3466.3 & $1712.0 \dagger$ \\
(g) & $(382.4)$ & $(926.9)$ \\
\hline
\end{tabular}

Results are mean $( \pm \mathrm{SD})$.

$* p<0.01 ; \dagger p<0.001$ AGA $v$ IUGR.

BMI, body mass index.

and by imaging the direction of flow by observing the bubbling effect produced by the injection of $2 \mathrm{~mL}$ of isotonic saline solution. A maternal sample was collected from the radial vein simultaneously to FBS.

Biochemical analyses and calculations. Lipids were extracted by the method of Folch et al. (20) and determined gravimetrically (21). Plasma fractions were separated by thinlayer chromatography. Total concentrations and percentage levels were measured in plasma, and then percentages of fatty acids were evaluated in PL, TG, and CE. For plasma lipids we refer to fatty acid composition of plasma total lipids, including PL, CE, TG, and the small fraction of FFA.

Lipid fractions (TG, PL, and CE) were separated on silica gel plates (Merck, Darmstadt, Germany) in chloroform/ methanol/glacial acetic acid/water (50:30:10:3 vol/vol/vol/ vol). Fatty acids were trans-esterified with methanolic hydrochloride and analyzed by high-resolution gas chromatography (Mega 2 GC, Fisons Instruments, Rodano, Italy), equipped with a flame ionization detector and fused silica capillary column (Supelco Omegawax 320, $30 \mathrm{~m}$ in length, $0.32 \mathrm{~mm}$ internal diameter, and $0.25-\mu \mathrm{m}$-thick film). Column temperature programing was increased from $60^{\circ} \mathrm{C}$ to $150^{\circ} \mathrm{C}$ by $10^{\circ} \mathrm{C} /$ min increments, from $150^{\circ} \mathrm{C}$ to $170^{\circ} \mathrm{C}$ by $5^{\circ} \mathrm{C} /$ min increments, and from $170^{\circ} \mathrm{C}$ to $235^{\circ} \mathrm{C}$ by $2^{\circ} \mathrm{C} / \mathrm{min}$ increments and held for $30 \mathrm{~min}$. Individual detector outputs were identified using pure reference compounds and by mass spectrometry (Trio 1000, Fisons Instruments, Italy) and expressed as weight percentage of fatty acid methyl esters. Peak areas were calculated on Chrom-Card software using heptadecanoic acid as internal standard. The detected molecules were $\mathrm{C}_{16: 0}, \mathrm{C}_{18: 0}$, and $\mathrm{C}_{24: 0}$ in the saturated class, $\mathrm{C}_{16: 1 \omega-7}, \mathrm{C}_{18: 1 \omega-9}, \mathrm{C}_{18: 1 \omega-7}$, and $\mathrm{C}_{24: 1 \omega-9}$ in the monounsaturated, and $\mathrm{C}_{18: 2 \omega-6}, \mathrm{C}_{18: 3 \omega-6}, \mathrm{C}_{18: 3 \omega-3}, \mathrm{C}_{20: 3}$ $\omega-9, \mathrm{C}_{20: 3 \omega-6}, \mathrm{C}_{20: 4 \omega-6}, \mathrm{C}_{20: 5 \omega-3}, \mathrm{C}_{22: 4 \omega-6}, \mathrm{C}_{22: 5 \omega-6}, \mathrm{C}_{22: 5 \omega-3}$, and $\mathrm{C}_{22: 6 \omega-3}$ in the polyunsaturated.

The EFA status was calculated as the ratio between the sum of the $\omega-3$ and $\omega-6$ fatty acids and the sum of the $\omega-7$ and $\omega-9$ fatty acids (22). The conversion ratio for $\omega-3$ and $\omega-6$ was calculated as the ratio between $\mathrm{AA}$ and $\mathrm{LA}\left(\mathrm{C}_{20: 4 \omega-6} / \mathrm{C}_{18: 2 \omega-6}\right)$ and the ratio between DHA and $\alpha \mathrm{LN}\left(\mathrm{C}_{22: 6} \omega_{-3} / \mathrm{C}_{18: 3} \omega_{-3}\right)$, respectively.

Statistical analysis. All results are expressed as mean \pm SD. The significance of the difference between groups was calculated with unpaired two-tailed $t$ test. The significance of the 
difference between maternal and fetal samples was calculated with a two-tailed $t$ test for paired samples. Linear regression analyses were performed by the least squares method. The limit of statistical significance was set at $p<0.05$.

\section{RESULTS}

Maternal and fetal fatty acids during gestation. Table 2 presents mean maternal and fetal plasma fatty acid concentrations in normal and IUGR pregnancies. In both groups absolute amounts of total plasma lipids were significantly higher in mothers than in fetuses, with a significant relationship between umbilical venous and maternal venous plasma concentrations (Fig. 1). Tables 3 and 4 present average relative percentages of fatty acids in maternal and fetal plasma, respectively, of normal and IUGR pregnancies.

No changes related to gestation were observed in maternal plasma fatty acid concentrations and percentages. Significant changes with gestation were observed for some fatty acids in normal fetuses. The saturated fatty acid palmitic acid $\left(\mathrm{C}_{16: 0}\right)$ increased significantly in plasma $\left(r^{2}=0.41 ; p<0.05\right)$ whereas the monounsaturated oleic acid $\left(\mathrm{C}_{18: 1 \omega-9}\right)$ decreased significantly $\left(r^{2}=0.62 ; p<0.01\right)$. The changes observed in some fetal fatty acids led to a significant increase in saturated $\left(r^{2}=\right.$ $0.56 ; p<0.05)$ and polyunsaturated fatty acids $\left(r^{2}=0.40 ; p\right.$ $<0.05)$ and a significant decrease in monounsaturated fatty acids $\left(r^{2}=0.62 ; p<0.01\right)$ in relation to gestation in normal fetuses. The plasma EFA status increased significantly in relation to gestation in both AGA and IUGR fetuses (Fig. 2), with no significant differences between AGA and IUGR. Inasmuch as no significant changes related to gestation were

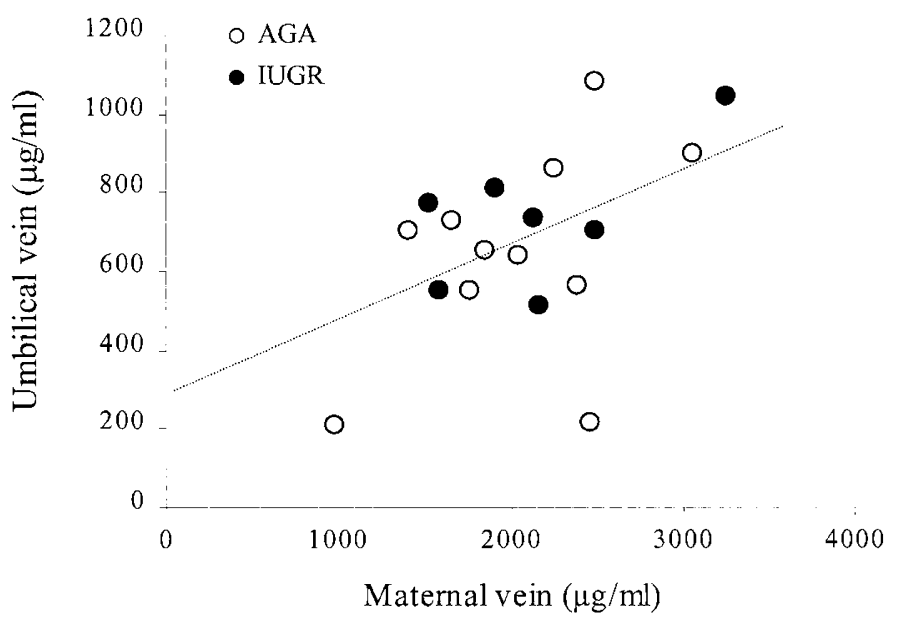

Figure 1. Relationship between umbilical venous and maternal venous plasma lipids (total concentrations) in AGA $(O)$ and IUGR $(\bullet)$ pregnancies $(y$ $\left.=251.22+0.20 x ; r^{2}=0.25 ; p<0.05\right)$.

observed in the EFA status in maternal plasma of both AGA $(1.47 \pm 0.28 \%)$ and IUGR $(1.40 \pm 0.24 \%)$ pregnancies, the $\mathrm{F} / \mathrm{M}$ ratio for EFA status increased significantly with gestation $\left(r^{2}=0.61 ; p<0.001\right)$. The percentages of LA $\left(\mathrm{C}_{18: 2 \omega-6}\right)$ and $\alpha \mathrm{LA}\left(\mathrm{C}_{18: 3 \omega-3}\right)$ were significantly higher in maternal compared with fetal plasma, whereas their main metabolites $\mathrm{AA}\left(\mathrm{C}_{20: 4}\right.$ $\omega-6)$ and DHA $\left(\mathrm{C}_{22: 6 \omega-3}\right)$ were significantly higher in fetal than in maternal plasma.

Comparison between normal and IUGR pregnancies. Although total plasma lipid concentrations were not significantly different in mothers and fetuses of IUGR compared with

Table 2. Maternal and fetal plasma lipid concentrations

\begin{tabular}{|c|c|c|c|c|}
\hline \multirow{2}{*}{$\begin{array}{l}\text { Fatty acids } \\
(\mu \mathrm{g} / \mathrm{mL})\end{array}$} & \multicolumn{2}{|c|}{ AGA } & \multicolumn{2}{|c|}{ IUGR } \\
\hline & Mothers & Fetuses & Mothers & Fetuses \\
\hline $\mathrm{C}_{14: 0}$ & $21.72 \pm 8.07$ & $3.51 \pm 2.29 \ddagger$ & $22.04 \pm 14.59$ & $4.52 \pm 2.72 *$ \\
\hline $\mathrm{C}_{18: 0}$ & $123.66 \pm 44.91$ & $60.29 \pm 29.32 \ddagger$ & $158.66 \pm 48.32$ & $69.94 \pm 19.05 \$$ \\
\hline $\mathrm{C}_{20: 0}$ & $2.78 \pm 1.54$ & $1.15 \pm 0.80 \ddagger$ & $3.62 \pm 1.86$ & $1.77 \pm 0.69 \dagger$ \\
\hline $\mathrm{C}_{22: 0}$ & $8.59 \pm 3.22$ & $2.10 \pm 1.20 \ddagger$ & $7.91 \pm 4.46$ & $2.45 \pm 1.93 \dagger$ \\
\hline $\mathrm{C}_{18: 1 \omega-9}$ & $409.42 \pm 189.59$ & $166.95 \pm 102.01 \ddagger$ & $453.65 \pm 154.08$ & $154.25 \pm 45.54 \dagger$ \\
\hline $\mathrm{C}_{18: 1 \omega-7}$ & $34.80 \pm 12.85$ & $23.37 \pm 12.78 \ddagger$ & $41.55 \pm 17.49$ & $21.13 \pm 7.11 \dagger$ \\
\hline $\mathrm{C}_{20: 1}$ & $3.49 \pm 1.50$ & $0.65 \pm 0.38 \ddagger$ & $4.84 \pm 1.64$ & $0.80 \pm 0.37 \ddagger$ \\
\hline $\mathrm{C}_{22: 1}$ & $0.96 \pm 0.61$ & $0.19 \pm 0.10 \ddagger$ & $0.55 \pm 0.34$ & $0.16 \pm 0.06^{*}$ \\
\hline $\mathrm{C}_{24: 1}$ & $14.29 \pm 5.85$ & $4.79 \pm 2.69 \$$ & $12.78 \pm 7.83$ & $4.70 \pm 3.34 \uparrow$ \\
\hline $\mathrm{C}_{20: 3 \omega-9}$ & $3.38 \pm 2.20$ & $2.65 \pm 2.59$ & $5.87 \pm 7.45$ & $2.51 \pm 0.94$ \\
\hline $\mathrm{C}_{22: 5 \omega-6}$ & $7.75 \pm 3.39$ & $4.17 \pm 2.45 \dagger$ & $11.92 \pm 8.53$ & $3.99 \pm 1.91^{*}$ \\
\hline $\mathrm{C}_{18: 3 \omega-3}$ & $4.81 \pm 2.24$ & $0.40 \pm 0.15 \$$ & $5.49 \pm 1.19$ & $0.56 \pm 0.23 t$ \\
\hline $\mathrm{C}_{20: 5 \omega-3}$ & $4.07 \pm 2.08$ & $1.86 \pm 1.31 \dagger$ & $6.78 \pm 3.54$ & $1.97 \pm 1.18 \dagger$ \\
\hline $\mathrm{C}_{22: 5 \omega-3}$ & $5.04 \pm 1.82$ & $1.07 \pm 0.56 \$$ & $7.26 \pm 3.12$ & $1.36 \pm 0.84 \$$ \\
\hline $\mathrm{C}_{22: 6 \omega-3}$ & $44.86 \pm 17.67$ & $23.73 \pm 13.58 \dagger$ & $62.24 \pm 24.58$ & $25.00 \pm 7.81 \dagger$ \\
\hline Total & $2028.83 \pm 532.68$ & $639.13 \pm 288.29 \ddagger$ & $2161.37 \pm 589.19$ & $731.47 \pm 175.79+$ \\
\hline
\end{tabular}

Values are expressed as mean $\pm \mathrm{SD}$.

$* p<0.05 ; \dagger p<0.01 ; \ddagger p<0.001$ mothers $v s$ fetuses. 
Table 3. Maternal fatty acid percentages in plasma and lipid fractions: IUGR versus AGA pregnancies

\begin{tabular}{|c|c|c|c|c|c|c|c|c|}
\hline \multirow[b]{2}{*}{ Fatty acids $\%$} & \multicolumn{2}{|c|}{ Plasma } & \multicolumn{2}{|c|}{ PL } & \multicolumn{2}{|c|}{ TG } & \multicolumn{2}{|c|}{ CES } \\
\hline & AGA & IUGR & AGA & IUGR & AGA & IUGR & AGA & IUGR \\
\hline $\mathrm{C}_{14: 0}$ & $1.05 \pm 0.25$ & $0.98 \pm 0.52$ & $0.52 \pm 0.07$ & $0.51 \pm 0.21$ & $1.97 \pm 0.69$ & $1.99 \pm 1.15$ & $0.92 \pm 0.23$ & $0.72 \pm 0.46$ \\
\hline $\mathrm{C}_{18: 0}$ & $6.34 \pm 1.33$ & $6.84 \pm 1.06$ & $11.06 \pm 2.10$ & $11.68 \pm 1.06$ & $3.74 \pm 2.00$ & $3.37 \pm 1.16$ & $1.73 \pm 0.96$ & $1.63 \pm 1.00$ \\
\hline $\mathrm{C}_{20: 0}$ & $0.17 \pm 0.08$ & $0.17 \pm 0.09$ & $0.25 \pm 0.12$ & $0.25 \pm 0.14$ & $0.10 \pm 0.06$ & $0.07 \pm 0.03$ & $0.06 \pm 0.03$ & $0.05 \pm 0.02$ \\
\hline $\mathrm{C}_{22: 0}$ & $0.43 \pm 0.15$ & $0.36 \pm 0.20$ & $0.80 \pm 0.43$ & $0.52 \pm 0.29$ & $0.11 \pm 0.07$ & $0.05 \pm 0.01$ & $0.10 \pm 0.14$ & $0.04 \pm 0.01$ \\
\hline $\mathrm{C}_{18: 1}$ & $21.19 \pm 3.44$ & $20.90 \pm 1.26$ & $12.13 \pm 1.74$ & $11.66 \pm 0.79$ & $37.47 \pm 4.45$ & $37.69 \pm 3.59$ & $20.79 \pm 2.60$ & $24.32 \pm 2.24 \dagger$ \\
\hline$C_{18: 1 \omega-7}$ & $1.84 \pm 0.50$ & $1.92 \pm 0.25$ & $1.65 \pm 0.30$ & $1.47 \pm 0.18$ & $2.98 \pm 0.89$ & $3.01 \pm 0.75$ & $1.82 \pm 0.83$ & $1.39 \pm 0.24$ \\
\hline $\mathrm{C}_{20: 1}$ & $0.19 \pm 0.05$ & $0.22 \pm 0.04$ & $0.17 \pm 0.05$ & $0.17 \pm 0.05$ & $0.42 \pm 0.10$ & $0.45 \pm 0.19$ & $0.05 \pm 0.07$ & $0.06 \pm 0.02$ \\
\hline $\mathrm{C}_{22: 1}$ & $0.04 \pm 0.03$ & $0.02 \pm 0.01 *$ & $0.07 \pm 0.04$ & $0.02 \pm 0.02$ & $0.03 \pm 0.02$ & $0.04 \pm 0.02$ & $0.06 \pm 0.06$ & $0.04 \pm 0.03$ \\
\hline $\mathrm{C}_{24: 1}$ & $0.72 \pm 0.29$ & $0.57 \pm 0.34$ & $1.31 \pm 0.62$ & $0.80 \pm 0.49$ & $0.20 \pm 0.34$ & $0.05 \pm 0.03$ & $0.16 \pm 0.32$ & $0.13 \pm 0.13$ \\
\hline $\mathrm{C}_{20: 3 \omega-9}$ & $0.17 \pm 0.07$ & $0.22 \pm 0.17$ & $0.20 \pm 0.13$ & $0.27 \pm 0.24$ & $0.17 \pm 0.06$ & $0.21 \pm 0.13$ & $0.14 \pm 0.20$ & $0.18 \pm 0.26$ \\
\hline $\mathrm{C}_{22: 5 \omega-6}$ & $0.36 \pm 0.11$ & $0.41 \pm 0.23$ & $0.48 \pm 0.13$ & $0.53 \pm 0.33$ & $0.13 \pm 0.04$ & $0.21 \pm 0.07 \dagger$ & $0.07 \pm 0.03$ & $0.07 \pm 0.03$ \\
\hline $\mathrm{C}_{18: 3 \omega-3}$ & $0.27 \pm 0.11$ & $0.36 \pm 0.18$ & $0.14 \pm 0.05$ & $0.17 \pm 0.08$ & $0.35 \pm 0.19$ & $0.44 \pm 0.18$ & $0.30 \pm 0.15$ & $0.41 \pm 0.19$ \\
\hline $\mathrm{C}_{20: 5 \omega-3}$ & $0.20 \pm 0.09$ & $0.31 \pm 0.15^{*}$ & $0.22 \pm 0.10$ & $0.35 \pm 0.21$ & $0.12 \pm 0.07$ & $0.13 \pm 0.08$ & $0.26 \pm 0.24$ & $0.32 \pm 0.20$ \\
\hline $\mathrm{C}_{22: 5 \omega-3}$ & $0.25 \pm 0.09$ & $0.35 \pm 0.10^{*}$ & $0.35 \pm 0.14$ & $0.47 \pm 0.18$ & $0.08 \pm 0.04$ & $0.10 \pm 0.09$ & $0.07 \pm 0.09$ & $0.02 \pm 0.02$ \\
\hline $\mathrm{C}_{22: 6 \omega-3}$ & $2.01 \pm 0.54$ & $2.72 \pm 1.01$ & $2.88 \pm 0.90$ & $3.48 \pm 1.45$ & $0.58 \pm 0.70$ & $0.61 \pm 0.58$ & $0.51 \pm 0.22$ & $0.62 \pm 0.28$ \\
\hline Saturated & $36.41 \pm 2.80$ & $37.71 \pm 3.84$ & $47.85 \pm 2.78$ & $48.90 \pm 3.70$ & $37.86 \pm 2.85$ & $38.78 \pm 5.96$ & $18.14 \pm 1.79$ & $16.78 \pm 6.45$ \\
\hline Monounsaturated & $25.88 \pm 3.49$ & $25.89 \pm 2.16$ & $16.05 \pm 2.00$ & $15.01 \pm 1.50$ & $44.15 \pm 4.91$ & $44.81 \pm 3.07$ & $25.73 \pm 3.33$ & $30.20 \pm 4.29 *$ \\
\hline Polyunsaturated & $37.71 \pm 4.18$ & $36.40 \pm 9.53$ & $36.10 \pm 3.13$ & $36.09 \pm 3.68$ & $17.99 \pm 5.37$ & $16.41 \pm 4.50$ & $56.13 \pm 4.12$ & $53.02 \pm 7.43$ \\
\hline
\end{tabular}

Values are expressed as mean $\pm \mathrm{SD}$.

$* p<0.05 ; \dagger p<0.01 ; \ddagger p<0.001$ AGA $v s$ IUGR.

Table 4. Fetal fatty acid percentages in plasma and lipid fractions: IUGR versus AGA pregnancies

\begin{tabular}{|c|c|c|c|c|c|c|c|c|}
\hline \multirow[b]{2}{*}{ Fatty acids $\%$} & \multicolumn{2}{|c|}{ Plasma } & \multicolumn{2}{|c|}{ PL } & \multicolumn{2}{|c|}{ TG } & \multicolumn{2}{|c|}{ CES } \\
\hline & AGA & IUGR & AGA & IUGR & AGA & IUGR & AGA & IUGR \\
\hline $\mathrm{C}_{14: 0}$ & $0.51 \pm 0.26$ & $0.20 \pm 0.21$ & $0.45 \pm 0.16$ & $0.46 \pm 0.19$ & $1.45 \pm 0.33$ & $1.28 \pm 0.38$ & $0.75 \pm 0.15$ & $0.71 \pm 0.15$ \\
\hline $\mathrm{C}_{18: 0}$ & $9.78 \pm 0.71$ & $8.93 \pm 1.21$ & $15.49 \pm 1.90$ & $14.80 \pm 0.84$ & $7.95 \pm 3.94$ & $7.69 \pm 3.80$ & $4.79 \pm 1.66$ & $4.73 \pm 2.61$ \\
\hline $\mathrm{C}_{20: 0}$ & $0.24 \pm 0.13$ & $0.25 \pm 0.11$ & $0.33 \pm 0.20$ & $0.37 \pm 0.17$ & $0.16 \pm 0.13$ & $0.18 \pm 0.09$ & $0.16 \pm 0.24$ & $0.06 \pm 0.03$ \\
\hline $\mathrm{C}_{22: 0}$ & $0.37 \pm 0.19$ & $0.32 \pm 0.21$ & $0.53 \pm 0.37$ & $0.58 \pm 0.45$ & $0.13 \pm 0.14$ & $0.13 \pm 0.09$ & $0.11 \pm 0.13$ & $0.03 \pm 0.01$ \\
\hline $\mathrm{C}_{18: 1 \omega-9}$ & $24.15 \pm 5.43$ & $20.92 \pm 3.16$ & $11.59 \pm 2.54$ & $9.93 \pm 1.74$ & $35.62 \pm 7.62$ & $30.49 \pm 6.18$ & $38.36 \pm 7.05$ & $34.22 \pm 7.12$ \\
\hline $\mathrm{C}_{18: 1 \omega-7}$ & $3.31 \pm 0.61$ & $2.97 \pm 0.49$ & $3.02 \pm 0.45$ & $2.86 \pm 0.32$ & $4.50 \pm 1.87$ & $3.83 \pm 1.46$ & $4.30 \pm 1.86$ & $3.36 \pm 0.85$ \\
\hline $\mathrm{C}_{20: 1}$ & $0.11 \pm 0.05$ & $0.11 \pm 0.05$ & $0.07 \pm 0.03$ & $0.08 \pm 0.03$ & $0.29 \pm 0.09$ & $0.28 \pm 0.11$ & $0.09 \pm 0.07$ & $0.06 \pm 0.02$ \\
\hline $\mathrm{C}_{22: 1}$ & $0.03 \pm 0.01$ & $0.02 \pm 0.01$ & $0.03 \pm 0.01$ & $0.02 \pm 0.01$ & $0.03 \pm 0.01$ & $0.13 \pm 0.01$ & $0.04 \pm 0.04$ & $0.02 \pm 0.01$ \\
\hline $\mathrm{C}_{24: 1}$ & $0.75 \pm 0.22$ & $0.62 \pm 0.35$ & $1.06 \pm 0.41$ & $0.90 \pm 0.53$ & $0.49 \pm 0.63$ & $0.17 \pm 0.13$ & $0.09 \pm 0.07$ & $0.06 \pm 0.06$ \\
\hline $\mathrm{C}_{20: 3 \omega-9}$ & $0.46 \pm 0.27$ & $0.38 \pm 0.11$ & $0.14 \pm 0.29$ & $0.34 \pm 0.13$ & $0.57 \pm 0.33$ & $0.49 \pm 0.17$ & $0.25 \pm 0.15$ & $0.61 \pm 1.30$ \\
\hline $\mathrm{C}_{22: 5 \omega-6}$ & $0.67 \pm 0.21$ & $0.44 \pm 0.22 *$ & $0.48 \pm 0.31$ & $0.34 \pm 0.16$ & $0.86 \pm 0.27$ & $0.81 \pm 0.18$ & $0.13 \pm 0.03$ & $0.12 \pm 0.02$ \\
\hline $\mathrm{C}_{18: 3 \omega-3}$ & $0.07 \pm 0.03$ & $0.15 \pm 0.12$ & $0.04 \pm 0.01$ & $0.05 \pm 0.03$ & $0.12 \pm 0.07$ & $0.16 \pm 0.14$ & $0.07 \pm 0.04$ & $0.25 \pm 0.50$ \\
\hline $\mathrm{C}_{20: 5 \omega-3}$ & $0.28 \pm 0.16$ & $0.27 \pm 0.12$ & $0.22 \pm 0.10$ & $0.19 \pm 0.11$ & $0.23 \pm 0.12$ & $0.24 \pm 0.12$ & $0.28 \pm 0.31$ & $0.42 \pm 0.68$ \\
\hline $\mathrm{C}_{22: 5 \omega-3}$ & $0.16 \pm 0.05$ & $0.23 \pm 0.13$ & $0.42 \pm 0.36$ & $0.20 \pm 0.10$ & $0.14 \pm 0.07$ & $0.18 \pm 0.18$ & $0.03 \pm 0.02$ & $0.02 \pm 0.02$ \\
\hline $\mathrm{C}_{22: 6 \omega-3}$ & $3.81 \pm 0.79$ & $3.29 \pm 0.79$ & $3.16 \pm 0.83$ & $2.89 \pm 0.67$ & $2.86 \pm 0.91$ & $2.85 \pm 1.86$ & $0.73 \pm 0.33$ & $1.18 \pm 1.20$ \\
\hline Saturated & $35.43 \pm 3.44$ & $37.73 \pm 2.64$ & $49.16 \pm 2.50$ & $51.38 \pm 2.01 *$ & $36.26 \pm 8.26$ & $39.98 \pm 5.32$ & $27.44 \pm 3.03$ & $28.80 \pm 2.14$ \\
\hline Monounsaturated & $31.73 \pm 5.82$ & $28.35 \pm 3.74$ & $16.93 \pm 2.96$ & $14.83 \pm 2.27$ & $46.19 \pm 10.30$ & $39.52 \pm 6.32$ & $49.96 \pm 7.95$ & $43.32 \pm 7.75$ \\
\hline Polyunsaturated & $32.84 \pm 3.18$ & $33.92 \pm 3.12$ & $33.91 \pm 2.73$ & $33.79 \pm 2.01$ & $17.55 \pm 3.31$ & $20.50 \pm 3.30$ & $22.60 \pm 5.79$ & $27.88 \pm 6.83$ \\
\hline
\end{tabular}

Values are expressed as mean $\pm \mathrm{SD}$.

$* p<0.05 ; \dagger p<0.01$ AGA $v s$ IUGR. 


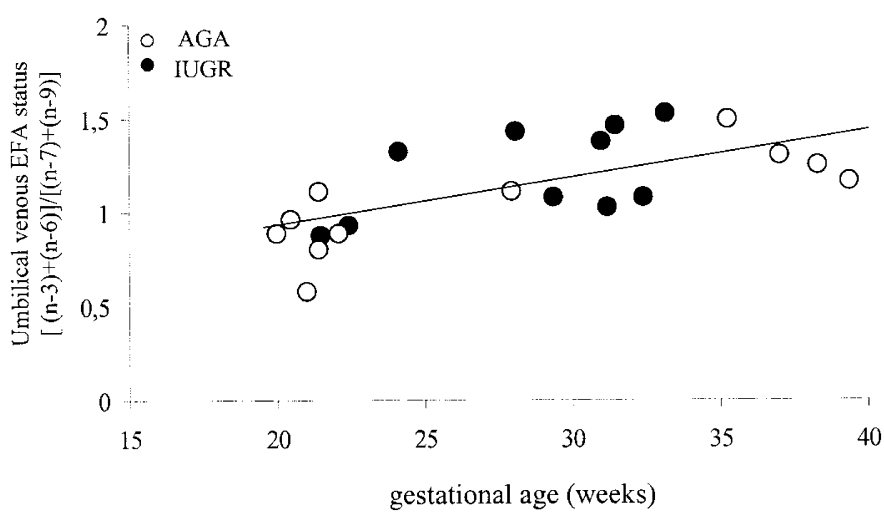

Figure 2. Relationship between umbilical venous EFA status $[(\omega-3+$ $\omega-6) /(\omega-7+\omega-9)]$ and gestational age for AGA $(\circ)$ and IUGR $(\bigcirc)$ fetuses $(y$ $\left.=0.38+0.027 x ; r^{2}=0.45 ; p<0.001\right)$.

normal pregnancies of comparable gestational age (Table 2), among $\omega-3$ and $\omega-6$ fatty acids significant differences were observed in the plasma fatty acid percent composition of maternal (Table 3) and fetal (Table 4) blood of IUGR compared with normal pregnancies. Significant differences were observed in maternal plasma of IUGR compared with normal pregnancies for the percentages of $\mathrm{C}_{22: 1}, \mathrm{C}_{18: 2 \omega-6}, \mathrm{C}_{20: 3 \omega-6}$, $\mathrm{C}_{22: 4 \omega-6}, \mathrm{C}_{20: 5 \omega-3}$, and $\mathrm{C}_{22: 5 \omega-3}$. The percentage of LA was also significantly lower in the PL fraction of IUGR compared with AGA mothers (Table 3).

In fetal plasma, significant differences were observed between AGA and IUGR for $\mathrm{C}_{16: 0}$ and $\mathrm{C}_{22: 5 \omega-6}$. The percentage of LA was significantly higher in the TG fraction of IUGR compared with AGA fetuses (Table 4).

The F/M ratio was significantly higher for the percentage of LA (AGA: $0.36 \pm 0.09 \%$; IUGR: $0.52 \pm 0.12 \% ; p<0.01$ ) and significantly lower for percentages of DHA (AGA: $1.94 \pm$ 0.32\%; IUGR: $1.25 \pm 0.19 \% ; p<0.001)$ and AA (AGA: 2.35 $\pm 0.35 \%$; IUGR: $2.04 \pm 0.3 \% ; p<0.05)$ in IUGR compared with normal pregnancies. The $\mathrm{F} / \mathrm{M}$ ratio for the conversion ratio of $\mathrm{AA} / \mathrm{LA}$ and of $\mathrm{DHA} / \alpha \mathrm{LA}$ were significantly lower in IUGR compared with normal pregnancies (AA/LA: AGA, 6.99 $\pm 2.42 \%$; IUGR, $4.11 \pm 1.19 \% ; p<0.01 ; \mathrm{DHA} / \alpha \mathrm{LA}:$ AGA, $8.03 \pm 3.12 \% ;$ IUGR, $4.35 \pm 2.33 \% ; p<0.01)$.

\section{DISCUSSION}

The present study investigates fetal-maternal fatty acid relationships in a relatively undisturbed condition throughout the second half of gestation. Our data confirm that, although total plasma fetal and maternal lipids are significantly related, the supply of fatty acids to the fetus is different from the fatty acid composition of maternal blood, with significantly lower fetal fatty acid concentrations and differences in the relative amounts of a number of fatty acids, supportive of significant placental handling.

In our study, the proportions of DHA and AA are significantly higher in the fetus than in the mother, whereas their precursors, LA and $\alpha \mathrm{LA}$ are proportionally higher in the mother than in the fetus. This is in agreement with a number of previous studies reporting that the proportions of AA and DHA are sharply increased across the placenta in term pregnancies
(17, 18, 23-26). Both total and relative maternal fatty acid concentrations did not change in the range of gestation studied, confirming that most changes in maternal plasma fatty acid composition occur in the first half of pregnancy (27). Therefore, the gestational changes observed in the fetal circulation cannot be accounted for by maternal changes. Rather, these differences could be related to developmental maturation either in placental transfer capabilities or in the conversion enzymes within the placenta or fetal liver. Most interestingly, we report a significant increase with gestation in plasma saturated and polyunsaturated fatty acids, whereas monounsaturated fatty acids decreased significantly. These changes led to a significant increase in fetal plasma LC-PUFA with gestation, suggesting a developmental maturation, and a possible role in premature delivery. Similar changes were recently reported in a large neonate population studied between 37 and 41 wk of gestation (28).

Fetal growth presents an exponential increase in the second half of gestation, with the fetus growing $1.5 \%$ per day (9). This growth is accompanied by significant changes in body composition as gestation advances, with a reduction in total body water concentration and a large and exponential increase in fat tissue deposition (29). From a nutritional point of view, in late gestation approximately $80 \%$ of the caloric needs for new tissue accretion are required for deposition of fat (9). Substantial differences in total body fat have been reported among fetuses with different patterns of intrauterine growth (9), consistent with the common observation that IUGR infants are born with reduced fat stores.

Interestingly, in our study this increase was similar in both normal fetuses and in IUGR fetuses. However, although no significant differences were observed in total fatty acid supply in both maternal and fetal plasma in IUGR compared with normal pregnancies, in IUGR the $\mathrm{F} / \mathrm{M}$ ratios for the relative amounts of DHA and AA were significantly lower than in normal pregnancies. One of the benefits of studying samples obtained in utero is the possibility of having control samples of similar gestational age as the IUGR, as data obtained at delivery are usually at different gestational ages between AGA and IUGR. However, similar results had been previously reported in a group of less severe small for gestational age fetuses studied at delivery after $34 \mathrm{wk}$ (30). Our data show that the proportion of the LC-PUFA metabolites AA and DHA to their precursors LA and $\alpha \mathrm{LA}$, respectively, was significantly decreased in fetal plasma of IUGR pregnancies relative to maternal plasma. In the last several years, evidence has accumulated suggesting that deficits of AA and DHA contribute to the neural and vascular complications of preterm infants. LCPUFA are constituents of the lipid bilayer and changes in their supply could provide the biochemical basis for the membrane disorders that characterize prematurity leading to immediate consequences such as intraventricular hemorrhage and retinopathy (31). These changes could also be associated with poor vascular development and the long-term consequences associated with IUGR (2-4).

It is interesting to note that both $\omega-3$ and $\omega-6$ LC-PUFA families present a decreased proportion of their derivatives, AA and DHA, compared with their precursors, LA and $\alpha \mathrm{LA}$, 
in fetal compared with maternal blood of IUGR pregnancies. This can be because of differences in placental uptake or differences in synthesis within the fetal-placental unit. However, studies performed in the perfused placenta do not support the presence of a significant conversion of AA and DHA from LA and $\alpha$ LA occurring in the placenta (32). We cannot exclude that the differences in the relative proportions of LC-PUFA in IUGR pregnancies could be accounted for by different maternal nutritional conditions. However, the percentage of LA was significantly lower in mothers of IUGR, in contrast to the significant increase found in the fetal circulation. Moreover, changes in maternal metabolism should also be considered for fatty acids, as has been demonstrated for amino acids in mothers of IUGR (6).

To our knowledge, this is the first study to investigate fetal-maternal fatty acid relationships in IUGR pregnancies sampled in utero. We have previously reported that IUGR is a condition associated with changes in placental transport of amino acids occurring early and independently from the presence of hypoxia or lactacidemia (7). Moreover, we have recently shown that fetal leptin concentrations, a hormone produced by fat and also by the placenta, are increased on a per kilogram basis in those IUGR fetuses with signs of hypoxia or lactacidemia (33). We may speculate that the changes that we describe in the relative supply of fetal fatty acids in IUGR pregnancies can be partly related to changes in transport occurring in relation to placental insufficiency. Moreover, placental or fetal conversion rates could also be influenced by changes in endocrine fetal status.

\section{CONCLUSIONS}

In conclusion, these data demonstrate that IUGR pregnancies are associated with significant changes in fetal-maternal fatty acid relationships. However, before recommending prophylactic measures in utero, which might perhaps reduce the risk of damages to the brain and retina, further studies are needed to elucidate the role of the placenta in fatty acid supply to the fetus and its relationships to fetal growth. In the meantime, IUGR infants could be considered for dietary LC-PUFA supplementation to restore a physiologic LC-PUFA composition of their body pools.

\section{REFERENCES}

1. Dekker GA, Sibai BM 1998 Etiology and pathogenesis of preeclampsia: current concepts. Am J Obstet Gynecol 179:1359-1375

2. Joseph KS, Kramer MS 1996 Review of the evidence on fetal and early childhood antecedents of adult chronic disease. Epidemiol Rev 18:158-184

3. Barker DJP 1998 In utero programming of chronic disease. Clin Sci 95:115-128

4. Barker DJP, Forsen T, Uutela A, Osmond C, Eriksson JG 2001 Size at birth and resilience to effects of poor living conditions in adult life: longitudinal study. BMJ 323:1273-1276
5. Cetin I, Corbetta C, Piceni Sereni L, Marconi AM, Bozzetti P, Pardi G, Battaglia FC 1990 Umbilical amino acid concentrations in normal and growth retarded fetuses sampled in utero by cordocentesis. Am J Obstet Gynecol 162:253-261

6. Cetin I, Ronzoni S, Marconi AM, Perugino G, Corbetta C, Battaglia FC, Pardi G 1996 Maternal concentrations and fetal-maternal concentration differences of plasma amino acids in normal and intrauterine growth retarded (IUGR) pregnancies. Am J Obstet Gynecol 174:1575-1583

7. Pardi G, Cetin I, Marconi AM, Lanfranchi A, Bozzetti P, Ferrazzi E, Buscaglia M, Battaglia FC 1993 Diagnostic value of blood sampling in fetuses with growth retardation. N Engl J Med 328:692-696

8. Enzi G, Zanardo V, Caretta F, Inelmen EM, Rubaltelli F 1981 Intrauterine growth and adipose tissue development. Am J Clin Nutr 34:785-790

9. Sparks JW, Ross JC, Cetin I 1998 Intrauterine growth and nutrition. In: Polin RA, Fox WW (eds) Fetal and Neonatal Physiology, 2nd ed. WB Saunders, pp 267-289

10. Clandinin MT, Chappell JE, Leong S, Heim T, Swyer PR, Chance GW 1980 Intrauterine fatty acid accretion rates in human brain: implications for fatty acid requirements. Early Hum Dev 4:121-129

11. Innis SM 1991 Essential fatty acids in growth and development. Prog Lipid Res 30:39-103

12. Giovannini M, Riva E, Agostoni C 1995 Fatty acids in pediatric nutrition. Pediatr Clin North Am 42:861-877

13. Sinclair AJ 1975 Long chain polyunsaturated FAs in the mammalian brain. Proc Nutr Soc 34:287-291

14. Greiner RC, Winter J, Nathanielsz PW, Brenna JT 1997 Brain docosahexaenoate accretion in fetal baboons: bioequivalence of dietary alpha-linolenic and docosahexaenoic acids. Pediatr Res 42:826-834

15. Haggarty P, Ashton JM, Joynson DR, Abramovich D, Page K 1999 The effect of maternal polyunsaturated fatty acid concentration on transport by the human placenta. Biol Neonate 75:350-359

16. Herrera E, Bonet B, Lasuncion MA 1988 Role of lipoprotein lipase activity on lipoprotein metabolism and the fate of circulating triglycerides in pregnancy. Am J Obstet Gynecol 158:15-75

17. Hendrickse W, Stammers JP, Hull D 1985 The transfer of free fatty acids across the human placenta. Br J Obstet Gynecol 92:945-952

18. Koletzko B, Muller J 1990 Cis- and trans-isomeric fatty acids in plasma lipids of newborn infants and their mothers. Biol Neonate 57:172-178

19. Parazzini F, Cortinovis I, Bortolus R, Fedele L 1991 Standard di peso alla nascita in Italia. Ann Ostet Ginecol Med Perinat 112:203-246

20. Folch J, Lees M, Stanley GHS 1957 A simple method for the isolation and purification of total lipids from animal tissue. J Biol Chem 226:497-509

21. Agostoni C, Trojan S, Bellù R, Bruzzese MG, Giovannini M 1997 Developmental quotients at 24 months and fatty acids composition of diet in the early infancy: a follow up study. Arch Dis Child 76:421-424

22. Hornstra G, Al MDM, Gerrard JM, Simonis MMG 1992 Essential fatty acid status of neonates born to Inuit mothers: comparison with Caucasian neonates and effect of diet. Prostaglandins Leukot Essent Fatty Acids 45:125-130

23. Olegard R, Svennerholm L 1970 Fatty acid composition of plasma and red cell phosphoglycerides in full term infants and their mothers. Acta Paediatr Scand 59:637-647

24. Friedman Z, Danon A, Lamberth EL, Mann WJ 1978 Cord blood fatty acid composition in infants and in their mothers during the third trimester. J Pediatr 92:461-466

25. Hoving EB, van Beusekom CM, Nijeboer HJ, Muskiet FA 1994 Gestational age dependency of essential fatty acids in cord plasma cholesterol esters and triglycerides. Pediatr Res 35:461-469

26. Berghaus TM, Demmelmair H, Koletzko B 2000 Essential fatty acids and their long-chain polyunsaturated metabolites in maternal and cord plasma triglycerides during late gestation. Biol Neonate 77:96-100

27. Al MDM, Van Houwelingen AC, Kester ADM, Hasaart THM, De Jong AEP, Hornstra G 1995 Maternal essential fatty acid patterns during normal pregnancy and their relationship to the neonatal essential fatty acid status. Br J Nutr 74:55-68

28. Rump P, Mensink RP, Kester ADM, Hornstra G 2001 Essential fatty acid composition of plasma phospholipids and birth weight: a study in term neonates. Am J Clin Nutr 73:796-806

29. Ziegler EE, O’Donnel AM, Nelson SE, Fomon SJ 1976 Body composition of the reference fetus. Growth 40:329-341

30. Vilbergsson G, Samsioe G, Wennergren M, Karlsson K 1991 Essential fatty acids in pregnancies complicated by intrauterine growth retardation. Int J Gynecol Obstet 36:277-286

31. Crawford MA, Costeloe K, Ghebremeskel K, Phylactos A, Skirvin L, Stacey F 1997 Are deficits of arachidonic and docosahexaenoic acids responsible for the neural and vascular complications of preterm babies? Am J Clin Nutr 66(suppl):1032S-1041S

32. Kuhn DC, Crawford MA 1986 Placental essential fatty acid transport and prostaglandin synthesis. Prog Lipid Res 25:345-353

33. Cetin I, Morpurgo PS, Radaelli T, Taricco E, Cortelazzi D, Bellotti M, Pardi G, Beck-Peccoz P 2000 Fetal plasma leptin concentration: relationship with different intrauterine growth patterns from 19 weeks to term. Pediatr Res 48:646-651 